\title{
Dysautonomia after traumatic brain injury: a forgotten syndrome?
}

Ian J Baguley, Jodie L Nicholls, Kim L Felmingham, Jenelle Crooks, Joseph A Gurka, Lauren D Wade

Abstract

Objectives-To better establish the clinical features, natural history, clinical management, and rehabilitation implications of dysautonomia after traumatic brain injury, and to highlight difficulties with previous nomenclature.

Methods-Retrospective file review on 35 patients with dysautonomia and 35 sex and Glasgow coma scale score matched controls. Groups were compared on injury details, CT findings, physiological indices, and evidence of infections over the first 28 days after injury, clinical progress, and rehabilitation outcome.

Results-the dysautonomia group were significantly worse than the control group on all variables studied except duration of stay in intensive care, the rate of clinically significant infections found, and changes (FIM) scores.

Conclusions-Dysautonomia is a distinct clinical syndrome, associated with severe diffuse axonal injury and preadmission hypoxia. It is associated with a poorer functional outcome; however, both the controls and patients with dysautonomia show a similar magnitude of improvement as measured by changes in FIM scores. It is argued that delayed recognition and treatment of dysautonomia results in a preventable increase in morbidity. (F Neurol Neurosurg Psychiatry 1999;67:39-43)

Keywords: traumatic brain injury; dysautonomia; autonomic dysfunction; dystonia
Alterations in autonomic function are well recognised in the acute recovery phase after traumatic brain injury. These transient changes include $33 \%$ of patients with tachypnoea greater than 30 breaths $/ \mathrm{min}, 25 \%$ with tachycardia above 120 beats $/ \mathrm{min}$, and $15 \%$ with systolic blood pressures above $160 \mathrm{~mm} \mathrm{Hg} .{ }^{1}$ However, a syndrome of prolonged episodes of autonomic abnormalities has been reported to follow a wide variety of different cerebral pathologies. Features of the syndrome include severe, paroxysmal increases in heart rate, respiratory rate, temperature, and blood pressure, with decerebrate or decorticate posturing, increased muscle tone, and profuse sweating. This syndrome has been variously termed autonomic dysfunction syndrome, ${ }^{23}$ autonomic or sympathetic storming, ${ }^{3-5}$ dysautonomia, ${ }^{4}{ }^{6}$ brainstem attack, ${ }^{7}$ hyperpyrexia associated with muscle contraction, ${ }^{8}$ hypothalamic-midbrain dysregulation syndrome, ${ }^{9}$ acute midbrain syndrome,${ }^{10}$ and diencephalic seizure. ${ }^{112}$ The syndrome will henceforth be referred to as dysautonomia.

Despite the dramatic presentation of the condition, literature reports of dysautonomia after traumatic brain injury consist of five papers recording details of 11 patients (table 1 ). Given the lack of a systematic nomenclature, a comprehensive literature review was performed for all aspects of altered autonomic function or tone after traumatic brain injury. This process yielded a further six patients in four papers with features consistent with dysautonomia, but in whom dysautonomia was not identified (table 1). These papers focused on isolated aspects of the overall syndrome-for example, metabolic expenditure, ${ }^{13}$ hypertension, ${ }^{14}$ early onset dysto- and in revised form

23 December 1998

Accepted 10 February 1999

ure cases of dysautonomia

\begin{tabular}{|c|c|c|c|c|c|c|c|c|c|c|c|c|}
\hline Author & $\begin{array}{l}\text { Case } \\
\text { No in } \\
\text { Study }\end{array}$ & $\begin{array}{l}\text { Age, } \\
\text { Sex }\end{array}$ & $G C S$ & $\begin{array}{l}\text { Temp } \\
{ }^{\circ} \mathrm{C}\end{array}$ & $\begin{array}{l}\text { Heart } \\
\text { Rate } \\
\text { Imin }\end{array}$ & $\begin{array}{l}B P \\
m m H g\end{array}$ & $\begin{array}{l}\text { Resp } \\
\text { Rate } \\
\text { /min }\end{array}$ & Posturing & Sweating & $\begin{array}{l}\text { Outcome } \\
\text { (GOS) }\end{array}$ & $\begin{array}{l}\text { Time of } \\
\text { Assessment }\end{array}$ & $C T$ \\
\hline \multirow[t]{3}{*}{ Rossitch $e t a l^{2}$} & 1 & & & $\mathrm{Y}$ & $\mathrm{Y}$ & $\mathrm{Y}$ & $\mathrm{Y}$ & $\mathrm{Y}$ & $\mathrm{Y}$ & $\leqslant 3$ & & \\
\hline & 3 & & & $\mathrm{Y}$ & $\mathrm{Y}$ & $\mathrm{Y}$ & $\mathrm{Y}$ & $\mathrm{N}$ & $\mathrm{Y}$ & $\leqslant 3$ & & \\
\hline & 5 & & & $\mathrm{Y}$ & $\mathrm{Y}$ & $\mathrm{Y}$ & $\mathrm{Y}$ & $\mathrm{Y}$ & $\mathrm{Y}$ & 5 & & \\
\hline \multirow[t]{2}{*}{ Rossitch et al ${ }^{11}$} & 2 & $24, M$ & 6 & 39.6 & 165 & $160 / 100$ & 52 & $\mathrm{Y}$ & $\mathrm{Y}$ & 4 & 6 & CC, blocked cisterns \\
\hline & 4 & $24, M$ & $<8$ & 39.6 & 103 & $170 / 80$ & 60 & $\mathrm{Y}$ & $\mathrm{Y}$ & $\leqslant 3$ & 3 & Normal \\
\hline Boeve $e t a \check{P}$ & 1 & $17, \mathrm{~F}$ & $<8$ & 42 & 190 & $170 /-$ & 40 & $\mathrm{Y}$ & $\mathrm{Y}$ & 3 & 8 & SAH, IVH, CC \\
\hline \multirow{3}{*}{ Strich et al } & 1 & $28, M$ & 5 & & & & & $\mathrm{Y}$ & $\mathrm{Y}$ & 3 & 8 & \\
\hline & 2 & $32, \mathrm{~F}$ & $<8$ & $\mathrm{Y}$ & & & $\mathrm{Y}$ & $\mathrm{Y}$ & $\mathrm{Y}$ & 3 & 4 & \\
\hline & 4 & $27, M$ & $<8$ & $\mathrm{Y}$ & & $\mathrm{Y}$ & & $\mathrm{Y}$ & $\mathrm{Y}$ & 3 & 6 & \\
\hline \multirow[t]{2}{*}{ Pranzatelli et al $\varphi^{9}$} & 2 & $7, \mathrm{M}$ & $<8$ & 39.3 & 160 & $150 / 105$ & 45 & $\mathrm{Y}$ & $\mathrm{Y}$ & $\leqslant 3$ & & Diffuse SAH \\
\hline & 3 & $19, M$ & $<8$ & 40 & 140 & $160 / 115$ & 40 & $\mathrm{Y}$ & $\mathrm{Y}$ & $\leqslant 3$ & & SAH, generalised oedema \\
\hline Chiloero $e t a l^{13}$ & 1 & $26, M$ & 6 & & 155 & & & $\mathrm{Y}$ & & 1 & 6 & $\mathrm{SDH}, \mathrm{CC}$ \\
\hline Sandel et $a l^{14}$ & 1 & $17, M$ & 8 & $\mathrm{Y}$ & 130 & $170 / 120$ & $\mathrm{~N}$ & $\mathrm{Y}$ & $\mathrm{Y}$ & 4 & 3 & $\mathrm{SAH}, \mathrm{CC}$ \\
\hline \multirow[t]{2}{*}{ Silver et $a l^{15}$} & 1 & $27, M$ & 6 & $\mathrm{Y}$ & $\mathrm{Y}$ & $\mathrm{Y}$ & $\mathrm{Y}$ & $\mathrm{Y}$ & $\mathrm{Y}$ & $2-3$ & 12 & $\mathrm{CC}$ \\
\hline & 2 & $25, \mathrm{~F}$ & 4 & $\mathrm{Y}$ & $\mathrm{Y}$ & $\mathrm{Y}$ & $\mathrm{Y}$ & $\mathrm{Y}$ & $\mathrm{Y}$ & 3 & & $\mathrm{SAH}, \mathrm{IVH}$ \\
\hline \multirow[t]{2}{*}{ Meythaler $e t a l^{16}$} & 1 & $20, \mathrm{~F}$ & 3 & 38.9 & & & & $\mathrm{Y}$ & $\mathrm{Y}$ & 3 & & Normal \\
\hline & 3 & $15, \mathrm{~F}$ & 4 & 40.6 & $\mathrm{Y}$ & & & & $\mathrm{Y}$ & & & IVH, DAI \\
\hline
\end{tabular}

GCS=Glasgow coma scale; $\mathrm{BP}=$ blood pressure; GOS=Glasgow outcome score; $\mathrm{SAH}=$ subarachnoid haemorrhage; IVH=intraventricular haemorrhage; $\mathrm{SDH}=$ subdural haemorrhage; $\mathrm{CC}=$ cortical contusion.

When available, the values of the various indices are reported. $Y=$ the reporting, but not the severity, of hyperthermia, tachycardia, hypertension, tachypnoea, posturing or sweating. $\mathrm{N}=$ absence of the symptom. Blank fields are included when data were not reported. Age is in years, time of assessment in months after injury. 
nia after traumatic brain injury, ${ }^{15}$ and fever of central origin. ${ }^{16}$

The literature on traumatic brain injury and dysautonomia focuses on small series of case reports or on anecdotal responses to a particular drug therapy. Minimal attention has been paid to the natural history, patterns of physiological changes, or outcomes of patients with dysautonomia. The limited outcome data (table 1) indicates a poor functional prognosis. Therefore, the aims of this study were to better establish the clinical features of dysautonomia in a larger series of patients, to evaluate the role that cerebral pathology, infection, and medications have in the aetiology of the condition, and to examine aspects of management and outcome of dysautonomia by comparison of patient groups with traumatic brain injury with and without dysautonomia.

\section{Methods}

PATIENTS

A retrospective file review was performed on 35 patients with traumatic brain injury with dysautonomia admitted to a rehabilitation service over a 10 year period. For the purposes of the study, dysautonomia was defined as simultaneous, paroxysmal increases in at least five out of the seven reported features of dysautonomia (heart rate, respiratory rate, temperature, blood pressure, posturing, dystonia, and sweating), with episodes persisting for at least 2 weeks after injury. The control group consisted of 35 subjects matched for sex and Glasgow coma scale (GCS) severity taken from a database of 121 consecutive inpatients with severe traumatic brain injury (maximum GCS score $\leqslant 8$ in the first 24 hours). Data were recorded on personal and injury related details, clinical progress, and rehabilitation outcome. Day of injury CT was used to diagnose brain stem and diffuse axonal injuries. Evidence supporting the diagnosis of diffuse axonal injuries included intraventricular haemorrhage, diffuse cerebral oedema, and multiple subcortical white matter or brainstem haemorrhages. Ambulance and emergency department reports were used to determine the presence or otherwise of preadmission hypotension and hypoxia. Physiological findings, haematology, and microbiology reports were reviewed for the first 28 days after injury. The dates that medications, particularly antibiotics, sedatives, and central acting drugs, were started or ended were also recorded.

\section{STATISTICAL ANALYSIS}

Analyses compared the dysautonomia group and the matched control group on baseline characteristics (age, sex, mode, and severity of injury), acute physiological and clinical presentation (maximum temperature and heart and respiratory rate, and white blood cell count over a 4 week acute recovery period; the presence or absence of tone, sweating, posturing, diffuse axonal injuries, brainstem injury, and preadmission hypotension and hypoxia) and outcome data (duration of stay in intensive care unit, rehabilitation and total time in hospital, Glasgow outcome scale (GOS), ${ }^{17}$ duration of post-traumatic amnesia (PTA; uti- lising the Westmead PTA scale $)^{18}$ and functional independence measure (FIM) ${ }^{19}$ scores on admission and discharge).

All continuous variables were corrected for outliers and non-normal distributions. Age distributions were compared using one way analyses of variance (ANOVAs) whereas continuous physiological records were analysed with two way repeated measures ANOVAs with group (dysautonomia $v$ control) as the between factor and time (weekly epochs) the within factor. Greenhouse-Geissner corrections were used to control for sphericity. Ordinal data (GCS, GOS, FIM) were analysed with the non-parametric Mann-Whitney $U$ test. Categorical data relating to sex and the presence or absence of clinical features were compared between groups using Fisher's exact $\chi^{2}$ test. Finally, the matched control group was compared on age, sex, and GCS criteria with the complete database of 121 patients with severe traumatic brain injury to test for representativeness of the sample.

\section{Results}

BASELINE CHARACTERISTICS

Table 2 presents the baseline characteristics for each group. There were no significant differences between the dysautonomia group and the matched control group for age, GCS score, sex, or mode of injury. All patients in the dysautonomia group and 34 out of 35 patients in the control group had closed head injuries. No patient in either group had evidence of spinal cord injury. Comparisons between the control group and the complete severe traumatic brain injury database did not show significant differences in sex $\left(\chi^{2}=0.31, \mathrm{p}>0.05\right)$ or GCS score $(U(1,138)=1.83, \mathrm{p}=0.177)$. A significant difference was found for age $(F(1,138)=29.6$, $\mathrm{p}=0.000)$ with the control mean age of 20.7 years significantly younger than the total sample mean of 35.1 years.

\section{ACUTE PHYSIOLOGICAL AND CLINICAL} PRESENTATION

The figure shows continuous physiological records for the dysautonomia and matched control group over the first 28 days after injury. Repeated measures ANOVAs showed that maximum temperature $(F(1,57)=44.8$, $\mathrm{p}=0.000)$, heart rate $(\mathrm{f}(1,59)=51.4, \mathrm{p}=0.000)$, and respiratory rate $(F(1,48)=9.1, \mathrm{p}=0.004)$ were significantly higher for the dysautonomia group than the control group. These main effects were qualified by significant time by group interactions in each of these measures. Maximum temperatures were significantly greater for the dysautonomia group in each of the four weekly epochs, with maximal group differences during weeks 2 and 3. Maximum

Table 2 Demographic and injury related data for dysautonomia group and control group

\begin{tabular}{llll}
\hline & Dysautonomia & Control & Significance \\
\hline Mean age (y) & 20.5 & 20.7 & NS \\
GCS score (median) & 4.0 & 3.0 & NS \\
Male/female ratio & $25 / 10$ & $25 / 10$ & NS \\
Mode of injury: & & $22 / 13$ & NS \\
$\quad$ Motor vehicle/other & $25 / 10$ & 2 & \\
\hline
\end{tabular}



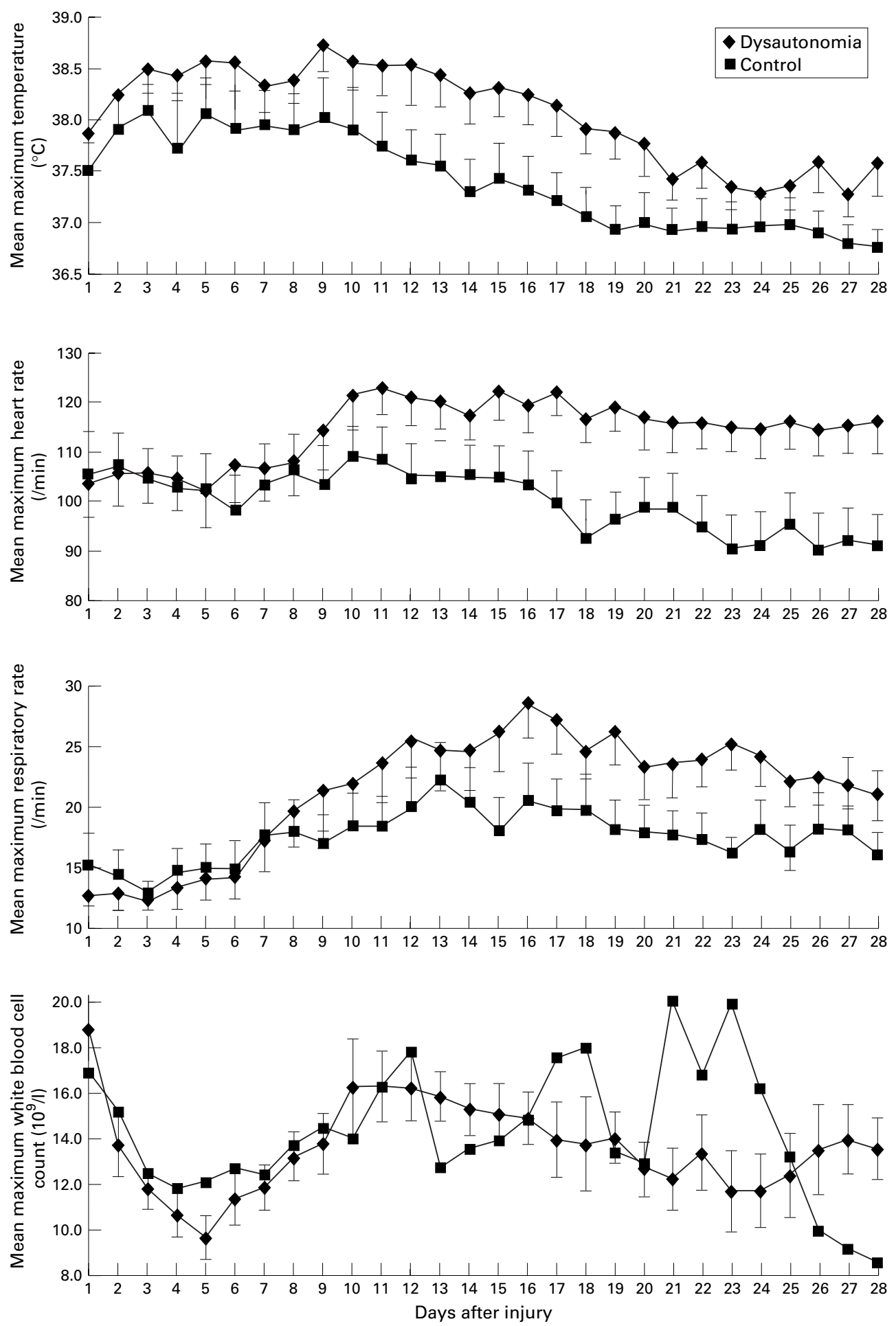

Physiological indices over the first 4 weeks. Error bars indicate the 95\% CI for each index identified.

heart rates were significantly higher in the dys- nor antibiotic use (dysautonomia=2.7, conautonomia group during weeks 2,3 , and 4 . Respiratory rates were lower for the dysautonomia group during the first week, but became significantly higher than controls in weeks 2 and 3.

By contrast, the maximum white cell count did not differ significantly between groups at any time period $(F(1,59)=0.26, \mathrm{p}=0.6099)$. Neither the mean number of microbiologically confirmed infections/patient (dysautonomia $=1.9$, control $=1.5 ; F(1,52)=0.86, \mathrm{p}=0.36)$ trol=3.0 courses of antibiotics/patient; $F(1,53)=0.49, \mathrm{p}=0.49)$ differed significantly between groups.

Table 3 presents categorical data comparing the presence or absence of clinically relevant symptoms for each group. Patients with dysautonomia presented with significantly greater reports of sweating, posturing, hypertension, and dystonias during recovery. Brain CT showed that patients with dysautonomia had significantly greater frequency of diffuse axonal 
Table 3 Number of clinical features present and absent in dysautonomia group and control group

\begin{tabular}{|c|c|c|c|c|c|}
\hline \multirow[b]{2}{*}{ Clinical feature } & \multicolumn{2}{|c|}{ Dysautonomia } & \multicolumn{2}{|l|}{ Control } & \multirow[b]{2}{*}{$\chi^{2} \operatorname{Result}$} \\
\hline & Present & Absent & Present & Absent & \\
\hline Sweating & 34 & 1 & 5 & 29 & $\chi^{2}=47.6, \mathrm{p}<0.005^{\star \star}$ \\
\hline Tone & 35 & 0 & 1 & 33 & $\chi^{2}=64.8, \mathrm{p}<0.005^{\star \star}$ \\
\hline Posturing & 25 & 10 & 6 & 29 & $\chi^{2}=20.9, p<0.005^{\star \star}$ \\
\hline Hypertension $>2$ weeks & 22 & 11 & 11 & 21 & $\chi^{2}=6.8, \mathrm{p}<0.05^{\star}$ \\
\hline Diffuse axonal injury & 32 & 3 & 23 & 11 & $\chi^{2}=6.03, p<0.025^{\star}$ \\
\hline Brainstem injuries & 11 & 24 & 4 & 30 & $\chi^{2}=3.9, \mathrm{p}<0.05^{\star}$ \\
\hline Pre-admission hypoxia & 22 & 13 & 9 & 26 & $\chi^{2}=9.9, \mathrm{p}<0.005^{\star \star}$ \\
\hline Pre-admission hypotension & 7 & 16 & 12 & 18 & $\chi^{2}=0.53, p>0.05$ \\
\hline
\end{tabular}

${ }^{\star} \mathrm{p}<0.05 ;{ }^{\star \star}<0.005$.

injuries and brain stem injuries than controls. There were significantly more reports of preadmission hypoxia, but not hypotension, in the dysautonomia group relative to controls.

OUTCOME DATA

Thirty one patients in the dysautonomia group had outcome data. Of the remaining four patients, two died in hospital, and two remain as inpatients. Table 4 presents outcome data for the two groups. The dysautonomia group had significantly longer rehabilitation and stay in hospital, but not duration of stay in the intensive care unit. The dysautonomia group had a significantly greater mean duration of PTA and greater number of subjects with chronic amnesia (those who do not emerge from PTA) or who could not be reliably tested. The outcome at discharge from rehabilitation was significantly worse for the dysautonomia group as reflected by scores on both the GOS and the FIM. Change in FIM scores (discharge minus admission FIM) were calculated for the dysautonomia and control groups. Both groups showed functional improvement during rehabilitation using the FIM as a dependent measure. Mann-Whitney $U$ tests on change in FIM scores found no significant differences between the two groups.

\section{DRUG MANAGEMENT}

Aside from medications used for sedation and paralysis, the use of centrally acting medications in the two groups varied dramatically. In the intensive care unit morphine and midazolam infusions were used in all patients in both dysautonomia and control groups. After stopping regular sedation, a wide range of drugs was used in an attempt to control dysautonomic features. These included, in decreasing order of frequency, chlorpromazine (14 patients), clonidine (nine), benzodiazepines (eight), propanolol (two), hydrallazine (one), and carbidopa/levodopa (one). This contrasts

Table 4 Outcome data for dysautonomia group and control groups

\begin{tabular}{llll}
\hline & $\begin{array}{l}\text { Dysautonomia } \\
\text { group }\end{array}$ & $\begin{array}{l}\text { Control } \\
\text { group }\end{array}$ & Significance \\
\hline Mean hospital DOS (days) & 267.9 & 69.2 & $F(1,64)=38.6, \mathrm{p}=0.000^{\star \star}$ \\
Mean ICU DOS (days) & 13.3 & 11.6 & $F(1,64)=0.413, \mathrm{p}=0.58$ \\
Mean rehabilitation DOS (days) & 206.8 & 44.1 & $F(1,58)=42.9, \mathrm{p}=0.000^{\star \star}$ \\
Mean PTA duration (days) & 124.4 & 36.6 & $F(1,43)=50.4, \mathrm{p}=0.000^{\star \star}$ \\
Median GOS score & 3 & 2 & $U(1,67)=84, \mathrm{p}=0.000^{\star \star}$ \\
Median discharge FIM & 60 & 119 & $U(1,48)=16, \mathrm{p}=0.000^{\star \star}$ \\
Mean FIM change score & 44.4 & 51.8 & $\mathrm{U}(1,48)=232, \mathrm{p}=0.41$ \\
Persistent amnesia (yes/no) & $21 / 12$ & $2 / 33$ & $\chi^{2}=25.3, \mathrm{p}<0.005^{\star \star}$ \\
\hline
\end{tabular}

DOS=Duration of stay; ICU $=$ intensive care unit.

${ }^{\star \star} \mathrm{p}<0.005$. with the control group, in which medications used were diazepam (five), chlorpromazine (one), and haloperidol (one). Twenty eight patients in the control group did not receive centrally acting agents.

\section{Discussion}

This paper provides supportive evidence that dysautonomia is a distinct clinical syndrome affecting a subgroup of patients with severe traumatic brain injury. It extends previous medical literature by noting consistencies in the clinical presentation of 35 patients and by comparing outcome with a matched control group. Patients with the condition have a different course of hospital stay and worse functional outcome. Both groups showed a similar magnitude of improvement as measured by change in FIM scores, albeit the improvement occurred at a slower rate in the dysautonomia group.

The data suggest that dysautonomia can be divided into three phases. During the first phase there is little to distinguish between the dysautonomia group and the control group. On average, this phase lasted 1 week and seemed to end with the cessation of regular paralysis or sedation. Phase two sees the onset of the physiological changes recognised as dysautonomia. This phase was taken to end with the cessation of sweating, with an average duration of 74 days after injury (SD 47.9, range 15-204). In phase three the paroxysmal episodes have burnt out, leaving dystonia and spasticity of varying severity. Two dysautonomic patients developed "locked in" syndrome ${ }^{20}$ on the basis of severe generalised dystonias, when communication only became possible due to voluntary control of an isolated muscle group (thumb in patient 20 , eye blink in 28 ). It would be possible to misinterpret such a patient's physical inability to communicate as evidence of absent cognitive function, resulting in an inappropriate diagnosis of persistent vegetative state.

Dysautonomia was particularly associated with severe diffuse axonal injury, preadmission hypoxia, younger age and, to a lesser extent, brainstem injury. The striking proportion of patients with both diffuse axonal and hypoxic injuries has not been previously reported. The results of the study do not support a role for infection in the aetiology of the syndrome, as there were no differences in white cell count patterns, infection rates, or antibiotic usage between the control group and the dysautonomia group. Similarly, medications with autonomic activity were not responsible for causing dysautonomia, as they were invariably prescribed after the onset of dysautonomia and in an attempt to minimise autonomic abnormalities.

Many of the features reported in this paper have the potential to increase secondary brain injury. An example of such an effect may be postinjury hyperthermia. In animal models, the threshold for secondary neuronal injury falls to $38^{\circ} \mathrm{C}^{21}$ How long the injured brain remains sensitive to hyperthermia has yet to be determined. In this study, $73 \%$ of patients with dysautonomia continued to have core tempera- 
tures above $38^{\circ} \mathrm{C} 2$ weeks after injury, falling to $24 \%$ at 4 weeks. In controls, these values were $18 \%$ and $3 \%$ respectively. Thus, temperature loading poses a much greater threat for secondary brain injury in patients with dysautonomia. In addition, "posturing" patients have dramatically increased energy expenditure, measured at $150 \%-200 \%$ in the first week, increasing to $200 \%$ to $250 \%$ in the second week. ${ }^{22}{ }^{23}$ Although not identified as dysautonomia, these extreme energy expenditure figures were from "invariably sweating, hypertonic patients who usually remained vegetative". ${ }^{22}$ The metabolic changes ${ }^{24}$ and posturing ${ }^{2125}$ are associated with increased noradrenaline concentrations. Noradrenaline produces permanent cardiac and skeletal muscle fibre damage and is an independent predictor of poor outcome after traumatic brain injury. ${ }^{26}$ Thus early recognition and treatment of dysautonomia has the potential to minimise secondary brain injury.

Although our findings extend previous literature, this study had several limitations. Data acquisition was retrospective and relied on documentation within medical records. It is considered that such documentation may underrepresent the frequency and severity of dysautonomic episodes after traumatic brain injury. Furthermore, the retrospective nature of our data prevented estimation of its incidence; nor was there an objective way of determining efficacy of the medications used. This study was limited to a single rehabilitation facility and the findings would benefit from confirmation in multicentre studies. Future research should focus on prospective analyses to improve understanding of the pathophysiology and aetiology of dysautonomia, thus optimising pharmacotherapy and rehabilitation interventions.

\section{Conclusion}

This paper describes the symptoms and clinical course of dysautonomia after severe traumatic brain injury. Dysautonomia seems to be a distinct clinical syndrome associated with a poorer outcome. It is argued that the features of dysautonomia may result in a preventable and unnecessary increase in morbidity. Early recognition and treatment of the condition is recommended to reduce long term disability. Research has been hampered by a lack of standardised diagnostic criteria and nomenclature. Systematic evaluation of treatment regimes are required to optimise the outcome of patients with dysautonomia.
This study did not receive funding in any form.

1 Jennett B, Teasdale G, Galbraith S, et al. Severe head injuries in three countries. $f$ Neurol Neurosurg Psychiatry 1977;40:291-8.

2 Rossitch E Jr, Bullard DE. The autonomic dysfunction syndrome: aetiology and treatment. Br F Neurosurg 1988;2: $471-8$.

3 Scott JS, Ockey RR, Holmes GE, et al. Autonomic dysfunction associated with locked in syndrome in a child. Arch Phys Med Rehabil 1997;78:200-3.

4 Ropper AH. Acute autonomic emergencies and autonomic storm. In: Low PA, editor. Clinical autonomic disorders. Boston: Little Brown, 1993:747-56.

5 Boeve BF, Wijdicks EFM, Benarroch EE, et al. Paroxysmal sympathetic storms (diencephalic seizures) after severe diffuse axonal head injury. Mayo Clin Proc 1998;73:148-52.

6 Fearnside MR, Cook RJ, McDougall P, et al. The Westmead head injury project outcome in severe head injury. A comparative analysis of pre-hospital, clinical and CT variables. Br f Neurosurg 1993;7:267-79.

7 Strich SJ. Diffuse degeneration of the cerebral white matter in severe dementia following head injury. I Neurol Neurosurg Psychiatry 1956;19:163-85.

8 Sneed RC. Hyperpyrexia associated with sustained muscle contractions: an alternative diagnosis to central fever. Arch Phys Med Rehabil 1995;76:101-3.

9 Pranzatelli MR, Pavlakis SG, Gould RJ, et al. Hypothalamicmidbrain dysregulation syndrome: hypertension, hypermidbrain dysregulation syndrome: hypertension, hyperrol 1991;6:115-22.

10 Klug N, Hoffmann O, Zierski J, et al. Decerebrate rigidity and vegetative signs in the acute midbrain syndrome with special regard to motor activity and intracranial pressure. Acta Neurochir 1984;74:219-33.

11 Bullard DE. Diencephalic seizures: responsiveness to bromocriptine and morphine. Ann Neurol 1987;21:609-11.

12 Soloman GE. Diencephalic autonomic epilepsy caused by a neoplasm. F Pediatr 1973;83:277-80.

13 Chiolero RL, Breitenstein E, Thorin D, et al. Effect of propanolol on resting metabolic rate after severe head injury. Crit Care Med 1989;17:328-34

14 Sandel ME, Abrams PL, Horn LJ. Hypertension after brain injury: case report. Arch Phys Med Rehabil 1986;67:469-72.

15 Silver JK, Lux WE. Early onset dystonia following traumatic Silver JK, Lux Wre. Early onset dystonia following tra
brain injury. Arch Phys Med Rehabil 1994;75:885-8.

16 Meythaler JM, Stinson AM. Fever of central origin in trauMeythaler JM, Stinson AM. Fever of central origin in trau-
matic brain injury controlled with propanolol. Arch Phys Med Rehabil 1994;75:816-8.

17 Jennett B, Snoek J, Bond MR, et al. Disability after severe head injury: observations on the use of the Glasgow outcome scale. F Neurol Neurosurg Psychiatry 1981;44:28592.

18 Shores EA, Marosszeky JE, Sandanam J, et al. Preliminary validation of a clinical scale for measuring the duration of post traumatic amnesia. Med F Aust 1986;144:569-72.

19 Keith RA, Granger CV, Hamilton BB, et al. The functional independence measure: a new tool for rehabilitation. In: Eisenberg MG, Gresiak RC, eds. Advances in clinical rehabilitation. Vol 1. New York: Springer, 1987:10-18.

20 Plum F, Posner JB. The diagnosis of stupor and coma. Philadelphia: FA Davis, 1996.

21 Wass CT, Lanier WL, Hofer RE, et al. Temperature changes of $\geqslant 1^{\circ} \mathrm{C}$ alter functional neurological outcome and histopathology in a canine model of complete cerebral ischaemia. Anesthesiology 1995;83:325-35.

22 Clifton Gl, Robertson CS, Choi SC. Assessment of nutritional requirements of head injured patients. 7 Neurosurg 1986;64:895-901.

23 Moore R, Najarian MP, Konvolinka CW. Measured energy consumption in severe head trauma. F Trauma 1989;29: 1633-6.

24 Clifton GL, Ziegler MG, Grossman RG. Circulating catecholamines and sympathetic activity after head injury. Neurosurgery 1981;8:10-14.

25 Shiozake T, Taneda M, Kishikawa M, et al. Transient and repetitive rises in blood pressure synchronised with plasma catecholamine increases after head injury. $f$ Neurosurg 1993; 78:501-4.

26 Hamill RW, Woolf PD, McDonald JV, et al. Catecholamines predict outcome in traumatic brain injury. Ann Neurol $1987 ; 21: 483-43$. 